\title{
INFLUENCES OF CHLORIDES ON VFA DISTILLATION DETERMINATION IN ANAEROBIC REACTION
}

\author{
ZENG, K. ${ }^{1}-$ XIE, H. $^{1}-$ LIU, S. ${ }^{2}-$ ZHANG, H. $^{1}-$ CUI, Y. ${ }^{1 *}$ \\ ${ }^{l}$ College of Water Conservancy \& Environmental Engineering, Zhengzhou University \\ 100 Science Road, Zhengzhou 450001, China \\ (phone: +86 0371-67781862; fax: +86 0371-67781315) \\ ${ }^{2}$ Henan Institute of Metallurgy Co. Ltd \\ 4 Yellow river north, Zhengzhou 450053, China \\ (phone: +86 0371-68327039; fax: +86 0371-68328676) \\ ${ }^{*}$ Corresponding author \\ e-mail: cuiyp@zzu.edu.cn (Cui Yanping) \\ (phone: +86 13613823874; fax: +86 0371-67781315) \\ (Received $3^{\text {rd }}$ Aug 2016; accepted $3^{\text {rd }}$ Oct 2016)
}

\begin{abstract}
In an experiment, an IC reactor was used to treat straw-washing wastewater from a paper mill; there appeared an acidification trend in this reactor due to accumulation of volatile fatty acid (short for VFA). In this paper, the influences of chlorides on VFA determination were investigated by detecting VFA in actual wastewater samples and imitated samples. The results showed that when wastewater samples were fed with sodium chloride standard solution, the determined VFA value increased by $12.9 \sim$ $38.4 \mathrm{mg} / \mathrm{L}$ relative to the samples not fed, and the addition of silver sulfate could shield the interference of chlorides on VFA detection. When standard samples containing different amounts of acetic acid but fed with the same amount of sodium chloride standard solution were used, chlorides showed an influence on VFA determination, and the increment of VFA value was between $35.1 \sim 40.3 \mathrm{mg} / \mathrm{L}$, which did not linearly correlate with the acetic acid concentration. When standard samples containing the same amount of acetic acid (500 or $700 \mathrm{mg} / \mathrm{L}$ ) but fed with different amounts of sodium chloride were used, the VFA value increased by $13.8 \sim 39.5 \mathrm{mg} / \mathrm{L}$ or $10.2 \sim 35.8 \mathrm{mg} / \mathrm{L}$, which linearly correlated with the amount of additional sodium chloride.
\end{abstract}

Keywords: anaerobic decomposition, chloride ions, IC reactor, wastewater treatment, distillation titration

\section{Introduction}

High concentration organic wastewaters, such as pulping and paper mill wastewater (Liu, 2012), soybean protein wastewater (Zeng et al., 2011) and starch desizing (Pei et al., 2015) wastewater, are generally treated with anaerobic biochemistry reactors such as UASB, IC, HABR (Pei et al., 2015; Yu, 2015; Wang et al., 2015). In anaerobic reaction, organic matter is usually broken into low-molecular organic matter (Michael et al., 2015) or volatile fatty acids (short for VFA). VFA is a semi-finished matter in anaerobic decomposition, from which the methanogen can produce methane. It is noticed that the methane produced by methanogen only accounts for a small fraction of methane produced by $\mathrm{H}_{2}$ and $\mathrm{CO}_{2}$. However, the generation of $\mathrm{H}_{2}$ and $\mathrm{CO}_{2}$ also occurs during the process where macromolecular organic compounds convert into VFA. Therefore, VFA is commonly used as a monitoring index of anaerobic reactor (Boonsawang et al., 2015; Kardos et al., 2011). When VFA accumulates in anaerobic reactors, methanogenic bacteria tend to be in an inactive situation, and then it is said that the reactors are undergoing acidification (Yu et al., 2011). Considering an IC 
reactor always requires a high organic loading rate (short for OLR) and a high level of methanation, it is necessary to control the VFA concentration more strictly (Zhao and Mu, 2014; Zeng et al., 2011).

Detection methods for VFA content mainly include colorimetric method, chromatography, titration method and distillation. Colorimetric method is suitable to detect single organic acid that is not mixed with organic acids, owing to its great interference and complex pretreatment (Jiang, 2010). Chromatography is difficult for use in a factory, because of its large investment cost, complex operating steps, difficult temperature control and high demand for technical staffs (Wang et al., 2008). Titration method for VFA, based on equilibrium theory of buffer solution, requires special test target and needs investigation for applying (Wang et al., 2008; Lutzhoft et al., 2014). By contrast, distillation or distillation titration method does not need complex delicate devices, and can be operated simply and reliably (Jiang, 2010), so that it has been generally used in running monitor of anaerobic treatment project.

Anaerobic treatment (Liu, 2012) in this paper was carried out by using the pilot scale apparatus and laboratory in a pulping and papermaking factory. An IC anaerobic reactor with a height of $5.5 \mathrm{~m}$ and an effective volume of $6 \mathrm{~m}^{3}$ was used to treat the straw-washing wastewater, and the influent flow in the experiment apparatus was 450 $\sim 550 \mathrm{~L} / \mathrm{h}$. Effluent VFA samples from this reactor were analyzed three times each day. When the running volume loading rate was $1.95 \sim 4.69 \mathrm{~kg} \mathrm{COD} /\left(\mathrm{m}^{3} \cdot \mathrm{d}\right)$, the effluent VFA concentrations in the reactor were $192.0 \sim 533.0 \mathrm{mg} / \mathrm{L}$; when the volume loading rate was $3.34 \sim 6.57 \mathrm{~kg} \operatorname{COD~} /\left(\mathrm{m}^{3} \cdot \mathrm{d}\right)$, the VFA concentrations were $724.0 \sim 1211.0 \mathrm{mg} / \mathrm{L}$. Obviously, the VFA concentrations were so high that a trend of acidification appeared in the reactor.

When treating straw-washing wastewater by an IC reactor, the main reasons why VFA values diverged and remained at a high level can be attributed to wastewater quality, running temperature, volume loading rate and $\mathrm{pH}$. However, it is not clear whether some other factors have influences on the VFA determination process. Liquid chlorides are commonly used to blend pulp in pulping and paper mills, and they can get into the paper mill wastewater through water supply, drainage and wastewater treatment system. The concentration of chlorides in this kind of wastewater is 3000 $\mathrm{mg} / \mathrm{L}$ approximately. In the distillation of water samples containing VFA, chloride ions and hydrogen ions can combine in the water form of hydrogen chloride under the acidification condition by adding phosphoric acid. With acidity and heating, hydrogen chloride is volatilized to gaseous state (Fritz and Fuget, 1956; Liu et al., 2012; Jiang, 2011), and then condenses and dissolves in the water in the condenser pipe, thus flowing into the receiving flask. Then, may these chlorides affect VFA detection? To the best of our knowledge, there is no relevant research paper on this topic up to now.

\section{Experimental methods and materials}

Wastewater samples were taken from the effluent of the anaerobic reactor in a factory (Liu, 2012). VFA standard solution and $\mathrm{NaCl}$ standard solution were prepared in laboratory as follows. 


\section{VFA standard solution}

Pipet $100 \mathrm{~mL}$ 99.5\% acetic acid of analytical reagents (AR) into a volumetric flask of $1 \mathrm{~L}$ and bring to the rated volume by distilled water, thus obtaining $10 \%$ acetic acid solution. Suck $50 \mathrm{~mL}$ such acetic acid solution into a volumetric flask of $500 \mathrm{~mL}$ and bring to the rated volume by distilled water, thus obtaining $1 \%$ acetic acid solution. The density of acetic acid is $1.0492 \mathrm{~kg} / \mathrm{L}$, and then $1 \%$ acetic acid solution contains acetic acid of $1.044 \mathrm{~g} / \mathrm{L}$, or $1.000 \mathrm{~g} / 0.9579 \mathrm{~L}$.

\section{$\mathrm{NaCl}$ standard solution (Chinese state administration of environmental protection, 2002)}

Put sodium chloride of guaranteed reagents (GR) into a crucible and heat it for $40 \sim 50 \mathrm{~min}$ at $600^{\circ} \mathrm{C}$. After cooling down, weigh $8.2400 \mathrm{~g}$ this sodium chloride and dissolve it in a proper amount of distilled water. Then, put the solution into a volumetric flask of $1 \mathrm{~L}$ and bring to the rated volume by distilled water. Pipet $100 \mathrm{~mL}$ new solution from this flask into a volumetric flask of $500 \mathrm{~mL}$ and bring to the rated volume by distilled water. Now, the standard solution contains sodium chloride of $1.00 \mathrm{~g} / \mathrm{L}$.

\section{Experimental method}

Different amounts of sodium chloride standard solution were fed into the real or imitated samples respectively, and the VFA values of the samples fed with chlorides or not were determined respectively. Thus, by comparing the VFA data, it was possible to analyze whether chlorides fed in the water samples had influences on VFA determination. In the contrast experiment, wastewater or water samples were also prepared, but without addition of sodium chloride standard solution.

Distillation and titration were carried out simultaneously on the parallel samples, and the determination data of VFA content was the available value (or the average value).

\section{VFA determination method}

There is no national standard method for VFA determination in water samples (Lutzhoft et al., 2014), and it usually refers to the distillation method in books (He, 1998). Main steps of the determination are as follows:

1) Put $100 \mathrm{~mL}$ water sample in which VFA concentration is less than $30 \mathrm{mmol}$ into a distillation flask, and add several drops of phenolphthalein.

2) Put $10 \% \mathrm{NaOH}$ into the distillation flask to make the sample liquor alkaline, and the addition of $\mathrm{NaOH}$ should be slightly in excess.

3) Distill the liquid volumes in the flask to $50 \sim 60 \mathrm{~mL}$ and then stop distillation.

4) Dilute the remaining fluid to original volume, and add $10 \mathrm{~mL} 8.5 \%$ phosphoric acid. Then, place the receiving flask with $10 \mathrm{~mL}$ distilled water under the condenser pipe of the distillation device, and ensure the tube of condenser pipe to be immersed in the liquid level of the receiving flask. Continue to distill until the remaining liquid is 15 20 mL. After the distillation flask cools down, add $50 \mathrm{~mL}$ distilled water in the distillation flask, and starts to distill again until the remaining liquid is $10 \sim 20 \mathrm{~mL}$.

5) Add 10 drops of phenolphthalein into the received liquor, and then titrate the liquor with $\mathrm{NaOH}$ standard solution. At endpoint, the ideal indicator color is a barely detectable shade of pale pink. 


\section{Materials and apparatus}

Analytical balance and glass devices used in VFA detection were delicate, and chemicals were analytical reagents (AR) or guaranteed reagents (GR) (Liu, 2012). The environment of laboratory was very exquisite. Table 1 shows the related apparatus, devices and chemicals.

Table 1. Apparatus, devices and chemicals

\begin{tabular}{ccc}
\hline $\begin{array}{c}\text { Name of apparatus, devices or } \\
\text { chemicals }\end{array}$ & Grade & Name of suppliers \\
\hline Analytical balance & FA2004N & Shanghai JinHai instrument Co., Ltd \\
PH meter & PHB-4 & Shanghai Precision \& Scientific instrument Co., Ltd \\
Constant temperature drying ovens & 202 & Beijing ZhongXing WeiYe instrument Co., Ltd \\
Acetic acid & AR & Beijing ShiJi TuoXin fine chemical Co., Ltd \\
Sodium chloride & GR & Luoyang HaoHua chemical reagent Co., Ltd \\
Sodium hydroxide & AR & Beijing ShiJi TuoXin fine chemical Co., Ltd \\
Phosphoric acid & AR & Beijing ShiJi TuoXin fine chemical Co., Ltd \\
Silver sulfate & AR & Luoyang HaoHua chemical reagent Co., Ltd \\
\hline
\end{tabular}

\section{Wastewater samples fed chlorides and detect VFA}

Effluent samples of the anaerobic reactor, in which VFA values were $160.0 \sim 293.5$ $\mathrm{mg} / \mathrm{L}$, were supplemented with sodium chloride standard solution of $200.0 \sim 800.0 \mathrm{mg} / \mathrm{L}$. The VFA values of the samples with or without chlorides were determined, and the differences between the values were calculated. The results are illustrated in Fig. 1, where C-CL represents the additional amount of sodium chloride standard solution, C-VFA represents the VFA concentration of effluent samples without adding sodium chloride, and I-VFA represents the increment of VFA determination values due to adding sodium chloride. Obviously, I-VFA = VFA values of effluent samples with adding sodium chloride - VFA values of these samples without adding sodium chloride. These notations are used in the whole paper, and the units are $\mathrm{mg} / \mathrm{L}$ for all.

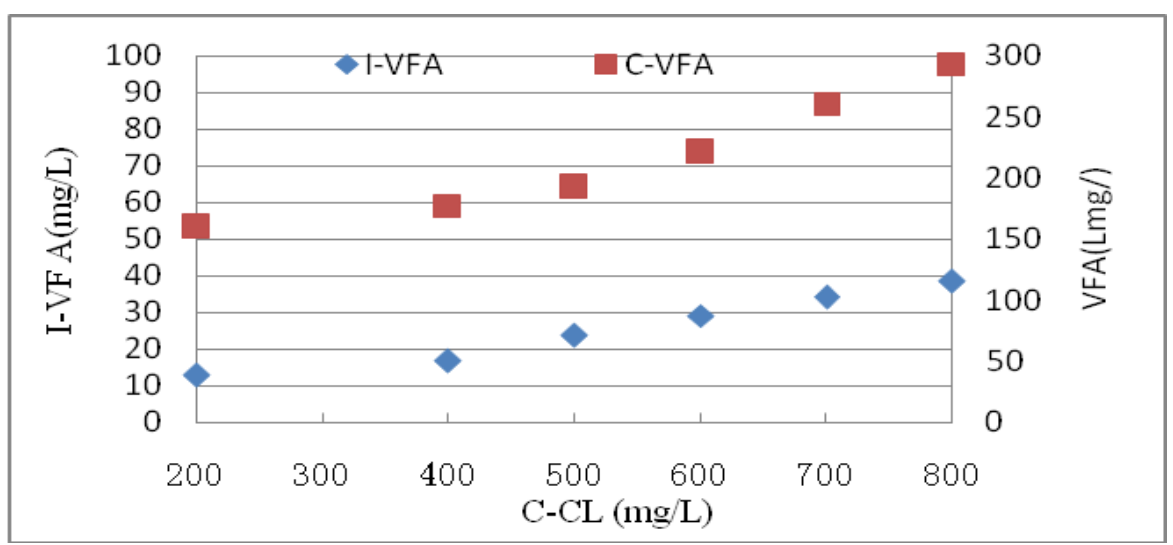

Figure 1. VFA increment for the wastewater samples with different amounts of chlorides

As can be seen from Fig. 1, when sodium chloride standard solution of 200.0, 400.0, $500.0,600.0,700.0$ and $800.0 \mathrm{mg} / \mathrm{L}$ is respectively added into the effluent samples, the 
determined VFA values of the samples increase continuously, with an increment of 12.9 $38.4 \mathrm{mg} / \mathrm{L}$. It is believed that when there are chloride ions in wastewater, the influences of chlorides in water quality test can be shielded by adding silver sulfate or mercuric sulfate (Liu and $\mathrm{Wu}, 2011$ ). Here, three samples were prepared to investigate the shielding effect: Sample A was confected with acetic acid of $1 \mathrm{~g} / \mathrm{L}$; Sample B was confected by feeding $3000 \mathrm{mg} / \mathrm{L}$ sodium chloride standard solution into Sample A; Sample C was confected by feeding $0.5 \mathrm{~g} / 100 \mathrm{~mL}$ silver sulfate (Dong and Jin, 2014) into Sample B. The VFA of the three samples were determined, and the results are provided in Table 2 (units are $\mathrm{mg} / \mathrm{L}$ ).

Table 2. VFA determination values of samples added with silver sulfate

\begin{tabular}{cccccc}
\hline & Sample A & Sample B & Sample C & B - A & B - C \\
\hline Test 1 (mg/L) & 986.0 & 1016.2 & 997.9 & 30.2 & 18.3 \\
Test 2 (mg/L) & 995.8 & 1031.0 & 1010.0 & 35.2 & 21.0 \\
\hline
\end{tabular}

As shown in Table 2, when Sample A is added with sodium chloride, the determined VFA values increase by 30.2 and $35.2 \mathrm{mg} / \mathrm{L}$ in Tests 1 and 2 respectively; when Sample B is added with silver sulfate, the determined VFA values decrease by 18.3 and $21.0 \mathrm{mg} / \mathrm{L}$ in Tests 1 and 2 respectively. Hence, for the detection of VFA, silver sulfate can be added to shield partially the influences of chlorides when there are chlorides in samples. Despite of this, it can however be seen from Fig. 1 and Table 2 that chlorides in samples always have influences on the determined VFA values.

In the detection of VFA, further research is needed to determine whether the method used in the determination of COD, which is based on shielding the influence of chlorides by adding silver sulfate, can be adopted (Liu and Wu, 2011). On this basis, the additional amount of silver sulfate can be estimated for optimizing the shielding reaction as well as the reducing effect.

\section{Distillation and detection of VFA values in samples with different acidity degrees}

Before the second distillation in VFA detection, water samples must be acidified by adding phosphoric acid. In order to find out the influences of chlorides with different acidity degrees on VFA determination, a group of contrasting tests were performed. Three imitated samples, in which the concentration of acetic acid was $100 \mathrm{mg} / \mathrm{L}$, were fed with different amounts of sodium chloride and phosphoric acid with a concentration of $8.5 \%$. For each chloride concentration, two adding dosages of phosphoric acid were used: $10 \mathrm{~mL}$ phosphoric acid (Dosage 1) and $20 \mathrm{~mL}$ phosphoric acid (Dosage 2). Table 3 shows the contrasting results, of which the units are $\mathrm{mg} / \mathrm{L}$.

Table 3. Increment of VFA values for differment amounts of phosphoric acid

\begin{tabular}{ccc}
\hline Chloride concentration & Dosage 1 & Dosage 2 \\
\hline 500 & 21.4 & 22.7 \\
1000 & 25.7 & 27.5 \\
2000 & 35.4 & 36.6 \\
\hline
\end{tabular}


As can be seen, with increasing chloride concentration from 500 to $2000 \mathrm{mg} / \mathrm{L}$, the detected VFA value presents an increasing trend. However, the distinction of VFA increment is slight when increasing the additional amount of phosphoric acid. It seems that phosphoric acid addition has no significant effect on VFA determination. In these experiments, however, it should be noticed that the additional amount of phosphoric acid is small, so that it cannot cause large variation of acidity to the distillate solution. Hence, further experiments are necessary to examine the influences of chlorides on VFA determination at different acidity degrees. However, theorists consider that the volatilization of hydrogen chloride from hydrochloric acid depends on the character, concentration and vapor pressure of hydrochloric acid, instead of the acidity degrees of hydrochloric acid.

\section{VFA detection of confected standard water samples}

\section{VFA detection of the samples containing different amounts of acetic acid}

A series of confected standard water samples fed with sodium chloride standard solution of $2000 \mathrm{mg} / \mathrm{L}$ but containing different amounts of acetic acid were tested for VFA determination, and their VFA values were compared with those samples containing different amounts of acetic acid but without sodium chloride. The differences in VFA values difference of these two series of samples, I-VFA, were deduced, and the relationship between the VFA increment and the acetic acid concentration is illustrated by Fig. 2, in which C-VFA represents the acetic acid concentration of the standard water samples, with units of $\mathrm{mg} / \mathrm{L}$; I-VFA/C-CL represents the ratio of the VFA increment and the amount of additional sodium chloride.

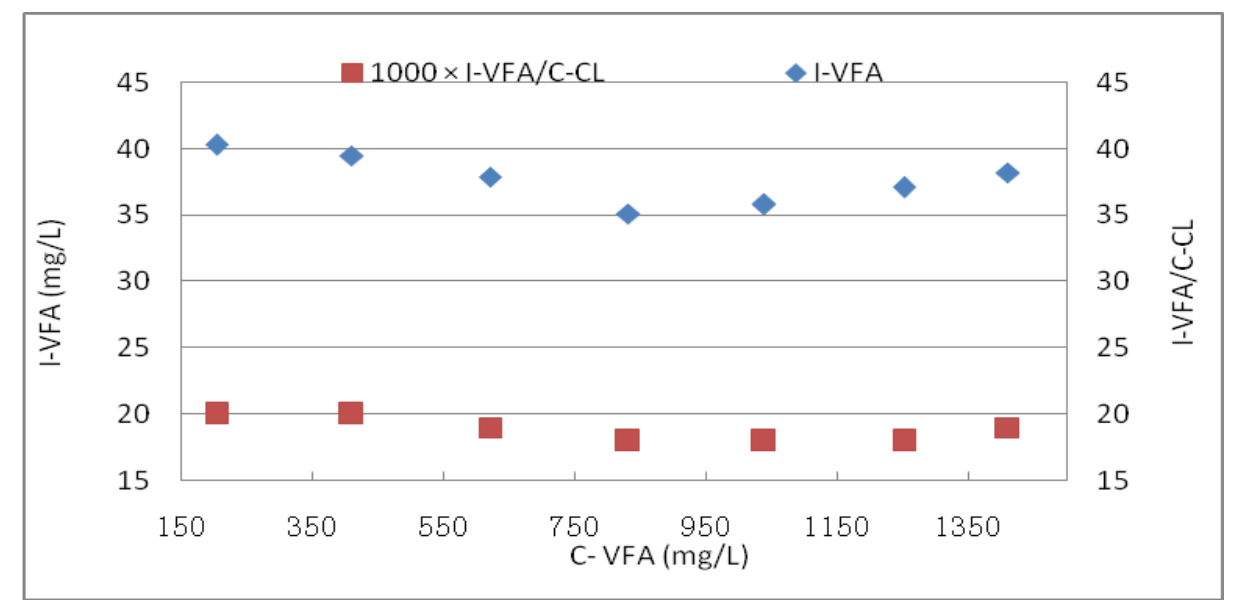

Figure 2. VFA increment of samples containing different amounts of acetic acid

As shown in Fig. 2, after the standard water samples containing acetic acid of different concentrations of 205.0, 410.0, 620.0, 835.0, 1044.0, 1250.0 and $1410.0 \mathrm{mg} / \mathrm{L}$ were fed with sodium chloride of $2000 \mathrm{mg} / \mathrm{L}$, the determined VFA values all increase, and the data range of I-VFA is $35.1 \sim 40.3 \mathrm{mg} / \mathrm{L}$. It is noted that the data range of VFA increment is only $5.2 \mathrm{mg} / \mathrm{L}$; meanwhile, the data range of I-VFA/C-CL is 0.002 . Hence, it can be declared that the data range is small for all samples. In addition, Fig. 2 also indicates that VFA increment is not linearly correlated with the acetic acid concentration. 


\section{VFA detection of the samples fed with different amounts of sodium chloride}

Standard samples containing acetic acid of 500 or $700 \mathrm{mg} / \mathrm{L}$, with different amounts of sodium chloride standard solution, were tested for VFA determination, and the relationship between the VFA increment relative to the sample without sodium chloride and the chloride concentration can be seen in Fig. 3. For the standard samples containing acetic acid of $500 \mathrm{mg} / \mathrm{L}$, when they were fed with sodium chloride standard solution of $200 \sim 2600 \mathrm{mg} / \mathrm{L}$, the determined VFA values all increase relative to the sample without sodium chloride, and the VFA increment is $13.8 \sim 39.5 \mathrm{mg} / \mathrm{L}$. For the standard samples containing acetic acid of $700 \mathrm{mg} / \mathrm{L}$, when they were fed with identical amount of sodium chloride, the VFA increment is $10.2 \sim 35.8 \mathrm{mg} / \mathrm{L}$. It can be seen that VFA increments determined in the samples with acetic acid of $500 \mathrm{mg} / \mathrm{L}$ are larger than those with acetic acid of $700 \mathrm{mg} / \mathrm{L}$. Besides, with increasing concentration of sodium chloride, the VFA increment presents an increasing trend, and shows a linear correlation with the amount of additional sodium chloride. In Fig. 3, I-VFA/C-CL data are from the samples containing acetic acid of $500 \mathrm{mg} / \mathrm{L}$. As can be seen, I-VFA/C-CL presents a decreasing trend when the sodium chloride concentration is increased.

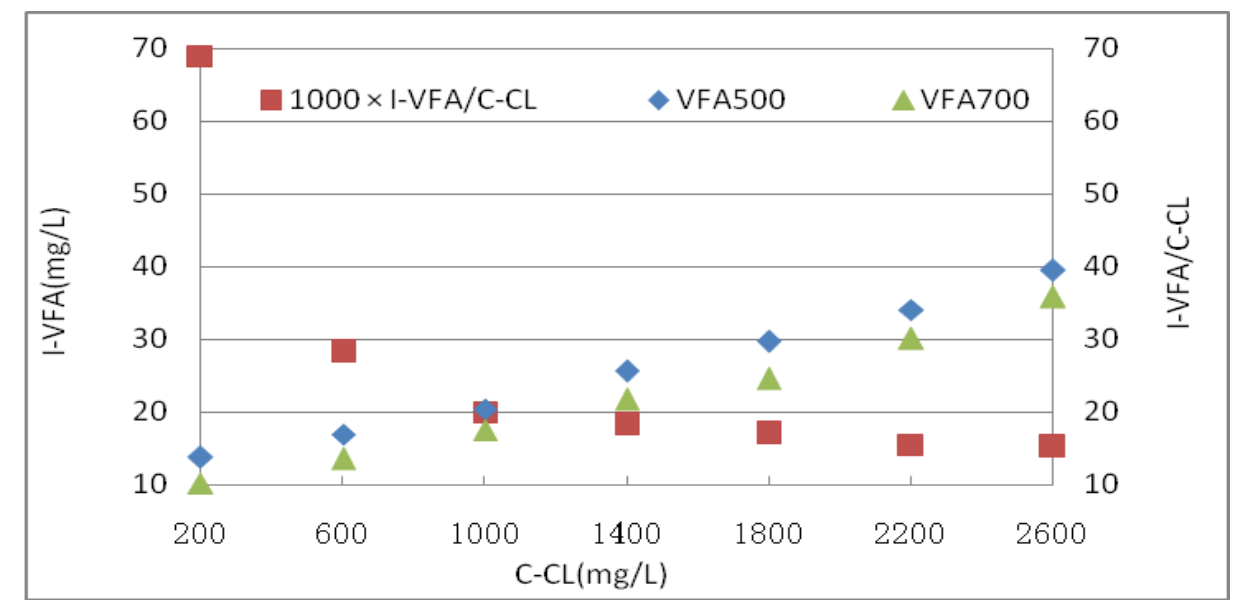

Figure 3. VFA increment of samples fed with different amounts of sodium chloride

\section{Conclusions}

When wastewater samples with VFA concentration of $160.0 \sim 293.5 \mathrm{mg} / \mathrm{L}$ were fed with sodium chloride standard solution, their determined VFA values showed an increasing trend, and the VFA increment was $12.9 \sim 38.4 \mathrm{mg} / \mathrm{L}$. After addition of $0.5 \mathrm{~g}$ silver sulfate, the influences of chlorides on VFA determination could be partially shielded. Hence, it can be concluded that chlorides always have an influence on VFA detection of water samples using distillation method.

When the confected standard samples containing acetic acid were fed with sodium chloride standard solution of $2000 \mathrm{mg} / \mathrm{L}$, chlorides only had a slight influence on VFA determination, with VFA increment of $35.1 \sim 40.3 \mathrm{mg} / \mathrm{L}$. The increment range is small in comparison with the amount of sodium chloride, and the VFA increment is not linearly correlated with the acetic acid concentration.

Addition of sodium chloride between $200.0 \sim 2600.0 \mathrm{mg} / \mathrm{L}$ into the standard samples containing acetic acid of 500 or $700 \mathrm{mg} / \mathrm{L}$ could result in a VFA increment between 
$13.8 \sim 39.5 \mathrm{mg} / \mathrm{L}$ or $10.2 \sim 35.8 \mathrm{mg} / \mathrm{L}$. With the increase of sodium chloride concentration, the increment of VFA also increased, and the VFA increment is linearly correlated with the amount of additional sodium chloride.

Acknowledgements. This research was supported by the project of "Major Science and Technology Program for Water Pollution Control and Treatment of China" (No. 2009ZX07210-002-001).

\section{REFERENCES}

[1] Boonsawang, P., Rerngnarong, A., Tongurai, C., Chaiprapat, S. (2015): Effect of pH, OLR, and HRT on performance of acidogenic and methanogenic reactors for treatment of biodiesel wastewater. - Desalination and Water Treatment 541 (12): 3317-3327.

[2] Dong, Z., Jin, X. (2014): Optimization of the Determination of CODcr in High-chlorine Wastewater by HACH Rapid Digestion Method. - Environmental protection of oil \& gas fields 24(4): 52-54.

[3] Fritz, J. J., Fuget, C. R. (1956): Vapor pressure of aqueous hydrogen chloride solutions, 0 ${ }^{\circ} \mathrm{C}$ to $50{ }^{\circ} \mathrm{C}$. - Journal of Chemical and Engineering Data 1(1):10-12.

[4] He, Y. (1998): Anaerobic biological treatment of wastewater. - China Light Industry Press, Beijing, China, 509-511.

[5] Jiang, W. (June 2010): The method for measuring the low concentrations of volatile fatty acid (VFA) in sewage and its application. - M.S. thesis, Chongqing University, Chongqing, China: $2-10$.

[6] Jiang, Q. (2011): Improvement of hydrogen chloride gas production in laboratory. Chemical engineering \& equipment 2:175-176.

[7] Kardos, L., Juhasz, A., Palkó, Gy., Oláh, J., Barkács, K., Záray, Gy. (2011): Comparing of mesophilic and thermophilic anaerobic fermented sewage sludge based on chemical and biochemocal tests. - Applied Ecology and Environmental Research 9(3): 293-302.

[8] Liu, J., Wu, H. (2011): Discussion on the determination of the COD of high chloridecontaining wastewater. - Industrial water treatment 31(4): 66-69.

[9] Liu, R., Qin, Y., Li, X., Liu, L. (2012): Concentrating aqueous hydrochloric acid by multiple-effect membrane distillation. - Frontiers of Chemical Science and Engineering 6(3):311-321.

[10] Liu, S. (June 2012): Experimental study on IC anaerobic reactor treating straw-washing wastewater in straw based pulping and papermaking. - M.S. thesis, Zhengzhou University, Zhengzhou, China: 5-6.

[11] Lutzhoft, H-C. H., Boe, K, Fang, C., Angelidaki, I. (2014): Comparison of VFA titration procedures used for monitoring the biogas process. - Water Research 54(5): 262-272.

[12] Pei, G., Yu, F., Liu, J. (2015): Feasibility study of individual treatments of desizing wastewater . - Journal of Residuals Science \& Technology 12(S1): 85-91.

[13] Recktenwald, M., Dey, E. S., Norrlöw, O. (2015): Improvement of industrial-scale anaerobic digestion by enzymes combined with chemical treatment. - Journal of Residuals Science \& Technology 12(4): 205-214.

[14] State administration of environmental protection. (2002): Monitoring and analysis methods of water and wastewater (the fourth edition). - Environmental Science Press, Beijing, China, 45-46.

[15] Wang, H., Lu, P., Ai, H., Zhang, D. (2008): Development of titration method for determining volatile fatty acids. - Environmental science \& technology 31(2): 47-50.

[16] Wang, J., Yan, J., Xu, W. (2015): Treatment of dyeing wastewater by MIC anaerobic reactor. - Biochemical Engineering JournaL 101 (9): 179-184.

[17] Yu, L., Peng, J., Sony, Y., Xu, D. (2011): Research progress in the acidification of highly efficient anaerobic reactor and its recovery. - Industrial water treatment 31(8): 1-4. 
[18] Yu, Y. (2015): Research on soybean protein wastewater treatment by the integrated twophase anaerobic reactor. - Saudi Journal of Biological Sciences 22 (5): 526-531.

[19] Zeng, K., Hou, Y., Cui, Y. (2011): The research of Square Internal Circulation Anaerobic Reactor to treatmenting soybean protein wastewater. - The 2nd International Conference on Multimedia Technology. hangzhou, July 26-28: 1329-1332.

[20] Zhao, L., Mu, X. (2014): The Research Progress and Application of IC Reactor. Guangdong chemical industry 41(20) : 75-76. 